\title{
Delayed innocent bystander cell death following hypoxia in Caenorhabditis elegans
}

\author{
C-L Sun ${ }^{1}, \mathrm{E} \mathrm{Kim}{ }^{1}$ and CM Crowder ${ }^{*, 1,2}$
}

After hypoxia, cells may die immediately or have a protracted course, living or dying depending on an incompletely understood set of cell autonomous and nonautonomous factors. In stroke, for example, some neurons are thought to die from direct hypoxic injury by cell autonomous primary mechanisms, whereas other so called innocent bystander neurons die from factors released from the primarily injured cells. A major limitation in identifying these factors is the inability of current in vivo models to selectively target a set of cells for hypoxic injury so that the primarily injured cells and the innocent bystanders are clearly delineated. In order to develop such a model, we generated transgenic Caenorhabditis elegans strains where 2-3\% of somatic cells were made selectively sensitive to hypoxia. This was accomplished by cell type-specific wild-type rescue in either pharyngeal myocytes or GABAergic neurons of a hypoxia resistance-producing translation factor mutation. Surprisingly, hypoxic targeting of these relatively small subsets of non-essential cells produced widespread innocent bystander cell injury, behavioral dysfunction and eventual organismal death. The hypoxic injury phenotypes of the myocyte or neuron sensitized strains were virtually identical. Using this model, we show that the $C$. elegans insulin receptor/FOXO transcription factor pathway improves survival when activated only after hypoxic injury and blocks innocent bystander death.

Cell Death and Differentiation (2014) 21, 557-567; do:10.1038/cdd.2013.176; published online 6 December 2013

Two fundamentally distinct mechanisms contribute to cell death following hypoxia. Cell autonomous mechanisms are better defined and include the final effectors of cell death such as necrosis and apoptosis pathways. ${ }^{1,2}$ On the other hand, injured cells can release molecules that promote secondary injury of other cells. For example, potassium and glutamate are two molecules released from hypoxic neurons that can promote death of surrounding neurons by a nonautonomous mechanism. ${ }^{3}$ Nonautonomous mechanisms are thought to be particularly important in less severe hypoxic conditions in which some cells remain initially viable. For example, in a focal ischemic stroke, neurons in the most hypoxic areas die early and are thought to promote the delayed death of less hypoxic, otherwise viable, neurons in the surrounding region termed the ischemic penumbra. ${ }^{4}$

C. elegans has been developed over the last decade as a genetically tractable model to study determinants of hypoxic cell death. ${ }^{5-10}$ Genetic screens in C. elegans have identified a considerable number of genes (termed hypoxia-resistant phenotype (Hyp) genes), whose reduction-of-function phenotype is resistance to organismal death following hypoxia. Although the discovery of these Hyp genes has served to implicate various pathways, particularly those regulating protein homeostasis, as essential to normal hypoxic sensitivity, fundamental aspects of Hyp gene function are unknown.
In particular, when the Hyp genes act relative to hypoxia to control survival is generally unknown. Genes that function after hypoxic exposure to control cell survival are categorically distinct from those acting only before or during hypoxia and potentially more relevant to mechanisms controlling delayed cell death. Additionally, cell autonomy or non-autonomy with regards to the Hyp phenotype has not been demonstrated for any of the genes. The identification of a set of genes that function in cell nonautonomous hypoxic injury would provide novel insight into the biology of hypoxic injury and might suggest new therapeutic approaches for scenarios where secondary hypoxic injury is thought to be prevalent, such as in stroke.

Here we describe the development of transgenic $C$. elegans strains where a hypoxia resistance-conferring mutation is rescued by the expression of the wild-type gene in a small subset of somatic cells. We initially hypothesized that the cells with the wild-type copy of the gene would be killed by hypoxia, whereas the surrounding cells with mutant gene expression would remain undamaged. In fact, what we found was widespread cell nonautonomous injury that occurred with a protracted time course. Thus, these strains provide the first genetically tractable model for cell nonautonomous hypoxic injury. We used these strains to determine whether a well-studied Hyp gene daf- $2^{9}$ can improve recovery when its

\footnotetext{
${ }^{1}$ Department of Anesthesiology, Washington University School of Medicine, St. Louis, MO, USA and ${ }^{2}$ Department of Developmental Biology, Washington University School of Medicine, St. Louis, MO 63110, USA

*Corresponding author: CM Crowder, Department of Anesthesiology, Washington University School of Medicine, 660 S. Euclid, St. Louis, MO 63110 , USA. Tel: + 1314747 0669; Fax: + 1314362 8579; E-mail:crowderm @morpheus.wustl.edu

Keywords: secondary hypoxic injury; ischemic penumbra; cell nonautonomous injury

Abbreviations: Hyp, hypoxia-resistant phenotype; PM, pharyngeal myocyte(s); GFP, green fluorescent protein; YFP, yellow fluorescent protein; Unc, uncoordinated phenotype; DAPI, 4',6-diamidino-2-phenylindole; PID, pharyngeal intestinal detachment phenotype; GABA, gamma-aminobutyric acid; GN, GABA neuron; EMC, enteric muscle contraction; pBoc, posterior body contraction; NGM, nutrient growth media; PCR, polymerase chain reaction; RNA, double stranded RNA-mediated interference; $\mathrm{SD}$, standard deviation

Received 16.8.13; revised 2.11.13; accepted 4.11.13; Edited by D Vaux; published online 06.12.13
} 
expression is reduced only after hypoxia and whether it acts to control innocent bystander cell injury.

\section{Results}

Selective hypoxic targeting of pharyngeal myocytes
produces delayed cell nonautonomous injury. In order to study cell-specific determinants of hypoxic injury in C. elegans, we set out to sensitize a subset of cells relative to the remainder. We utilized rars-1(gc47), a missense reduction-of-function mutation in the cytoplasmic arginyl tRNAsynthetase gene rars-1 that was isolated in a mutagenesis screen for resistance to hypoxic organismal death. ${ }^{8}$ The gc47 mutant is fully resistant to hypoxic exposures that kill $100 \%$ of wild-type animals, and this hypoxia-resistant phenotype is rescued by the expression of wild-type rars-1 driven under its native promoter. ${ }^{8}$ Given its function as the only cytoplasmic arginyl tRNA-synthetase, rars-1 should function in all cells to support protein translation. Thus, we reasoned that expression of wild-type rars-1 in a small subset of non-vital cells in the rars-1(gc47) background would fully restore hypoxic sensitivity to these cells and allow the study of cell-specific determinants of hypoxic injury in an alive, genetically tractable animal.

We first targeted pharyngeal myocytes (PM-targeted) for hypoxic injury for various reasons. PMs are contained within the pharynx, an easily identifiable organ that mediates a feeding behavior that is simple to score. ${ }^{11}$ The 68 cells of the pharynx, including the 20 myocytes, are contained within their own basal lamina. ${ }^{11,12}$ The myocytes are capable of mediating a basal rate of pharyngeal pumping autonomously; ${ }^{13-17}$ the 20 neurons within the pharynx regulate but are not required for pumping and function without input from the rest of the $C$. elegans nervous system. Pharyngeal pumping behavior can be largely disrupted without organismal lethality. ${ }^{11}$ PMs generate action potentials with a frequency range of $1-5 \mathrm{hz}$ and as such resemble mammalian hypoxia sensitive excitable cells such as cardiac myocytes and neurons. ${ }^{16}$

C. elegans strains containing integrated transgenes expressing full-length wild-type rars-1 cDNA with yellow fluorescent protein (YFP) ( $g c / s 3)$ or YFP alone (gcSi2) in $\mathrm{PMs}$ driven by the myo-2 promoter $^{18}$ were generated by $\mathrm{MosSCl}$ transposon-mediated transformation and placed in the rars-1(gc47) background (Figure 1a). ${ }^{19,20}$ Specificity of myo-2 promoter expression in PMs was confirmed by fluorescence in gcSi2, gcls3, and in oxls34, a high copy number Pmyo-2::green fluorescent protein (GFP) integrant (Supplementary Figures $1 \mathrm{a}-\mathrm{i}$ ). ${ }^{21}$ After a $24 \mathrm{~h}$ recovery from a hypoxic exposure that kills all wild-type animals, less than $5 \%$ of rars-1(gc47);gcls3 animals were dead and almost all of the alive animals appeared healthy and were moving normally (Figure 1b). However, as would be expected for cell autonomous injury of the PMs, the $g c 47 ; g c l s 3$ animals had a nearly fully penetrant, severe pumping rate defect after $24 \mathrm{~h}$ of recovery from hypoxia (Figure 1c). The majority of the animals in the hypoxia-resistant control strains rars-1(gc47) and gc47;gcSi2 had a pumping rate similar to or only slightly lower than that after recovery from normoxic incubations (Figure 1c). With more prolonged recovery, an increasing fraction of $g c 47 ; g c l s 3$ animals became severely uncoordinated (Unc) and then died (Figures 1b,d and e). The movement phenotypes tended to be bimodal; a significant fraction of the animals moved at an almost normal speed, whereas the remainder moved at best threefold slower, most more than ten-fold slower (Figures 1d and e, Supplementary Video 1-3, Table 1). Given that PMs have no role in C. elegans locomotion, this movement defect must be due to cell nonautonomous mechanisms.

A small subset of the surviving rars-1(gc47); gcls3 had an unusual appearance after $48 \mathrm{~h}$ of recovery from hypoxia. These animals had a ground glass appearance extending posterior to the pharynx for as much as half of the animal (Figure 2a); by $96 \mathrm{~h}$ of recovery about $25 \%$ of the hypoxiatreated animals had this appearance (Figure $2 b$ ). This region looked devoid of cells but was stained with the DNA-binding dye 4',6-diamidino-2-phenylindole (DAPI) (Figure 2c). We hypothesized that either the intestine was massively distended in these animals or that the intestine was detached from the pharynx and that ingested bacteria filled this space. Feeding with m-cherry-labeled bacteria confirmed intestinal detachment with $\mathrm{m}$-cherry spreading through the pseudocoelomic space when fed after hypoxia (Figure 2d) and filling the intestine if fed before hypoxia (Figure 2e); thus, we called this phenotype PID (pharyngeal intestinal detachment). One potential etiology for PID was that live bacteria, having managed to escape cell rupture because of PM defects, were able to divide in the gut then cause its rupture. Feeding animals live bacteria during the recovery phase after hypoxia did increase PID penetrance, although PID animals were still observed after feeding with heat-killed bacteria or even no bacteria (Figure 2f). Thus, gut distention then rupture by dividing bacteria is not essential to the etiology of PID. The fraction of Unc animals was not significantly affected by the nature of the recovery food (live, heat-killed or no bacteria), and the fraction of Unc animals was at least double of those with PID (Figure $2 \mathrm{~g}$ ). Thus, PID was not necessary to produce the Unc phenotype after hypoxia.

Relative hypoxic sensitization of GABA neurons produces hypoxic phenotypes indistinguishable from PM-targeting. In order to study primary hypoxic injury of neurons in $C$. elegans, we targeted the GABAergic neurons by driving expression of rars-1 $(+)$ with the gamma-aminobutyric acid (GABA) neuron-specific unc-47 promoter in the rars-1(gc47) background. unc-47 encodes a transmembrane vesicular GABA transporter exclusively expressed in the GABAergic neurons (Supplementary Figures $1 \mathrm{j}-1) .^{22}$ The C. elegans GABAergic nervous system consists of 26 neurons, 23 of which provide inhibitory synaptic input onto body wall and head myocytes. ${ }^{23}$ These inhibitory motor neurons control contralateral relaxation of muscles during sinusoidal and head foraging movements but are not essential for locomotion or foraging. Two other GABA neurons (GN) synapse onto enteric muscles and stimulate defecation. The remaining GN is an interneuron with no known function. The GABAergic neurons do not control pharyngeal pumping rate, and laser ablation of GNs or mutations that abolish all GABAergic transmission do not reduce animal viability. ${ }^{23,24}$ Thus, we anticipated a distinct set of phenotypes in the 

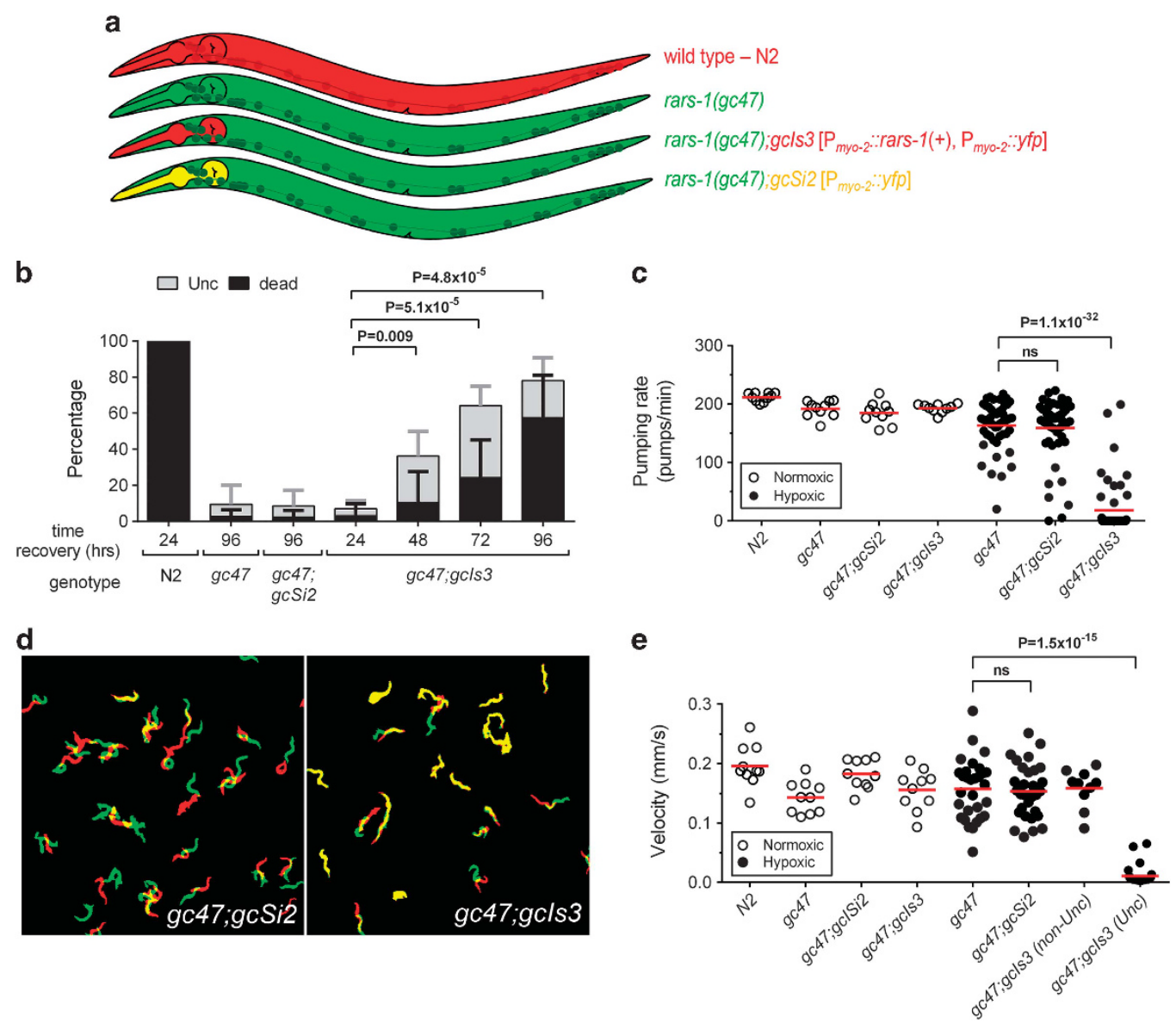

Figure 1 Hypoxic injury phenotypes of PM-targeted animals. (a) Schematic representation of PM-targeted model. (b) Unc phenotype and delayed organismal death after various recovery times from a $21 \mathrm{~h}$ hypoxic incubation. Wild-type N2 and the genotypes tested are indicated. Bars represent mean \pm S.D. of seven independent experiments ( $n \geqq 355$ animals). $P$-values are by two-tailed $t$-test for sum of the $\%$ Unc and dead. Corresponding $P$-values for $\%$ dead are: $48 \mathrm{~h}-P=0.12,72 \mathrm{~h}-P=0.012$ and $96 \mathrm{~h}-P=0.00035$. For \% Unc are: $48 \mathrm{~h}-P=0.0012,72 \mathrm{~h}-P=9.7 \times 10^{-5}$ and $96 \mathrm{~h}-P=0.026$. (c) Hypoxic pumping defect. Quantification of the pharyngeal pumping rate of animals with indicated genotypes after a $24 \mathrm{~h}$ recovery from normoxic or hypoxic incubation. Red line indicates mean of $n=10$ animals and 30 for normoxic (one trial) and hypoxic condition (three trials, $n=10$ per trial for each strain tested), respectively. $P$-values are by two-tailed $t$-test; ns, not significant. (d and e) Hypoxic Unc phenotype. Time lapse images (red @ time 0 and green 30 s later) were taken after a $72 \mathrm{~h}$ recovery from hypoxia and overlaid. Velocity assay quantifying Unc phenotype of animals with indicated genotypes after a $72 \mathrm{~h}$ recovery from normoxic or hypoxic incubation. All hypoxic gc47:gcls3 animals were categorized as either non-Unc (non-Unc) or Unc and assayed separately. Red line indicates mean of $n=10$ and 30 for normoxic (one trial) and hypoxic condition (three trials, $n=10$ per trial for each strain tested), respectively. $n=10$ (one trial) for hypoxic non-Unc gc47;gcls3 animals. $P$-values are by two-tailed $t$-test; ns, not significant

Table 1 Hypoxic phenotypes of selectively targeted strains

\begin{tabular}{|c|c|c|c|c|c|}
\hline \multirow[t]{2}{*}{ Phenotype } & \multirow[t]{2}{*}{ Recovery time ${ }^{a}$} & \multicolumn{4}{|c|}{ Genotypes } \\
\hline & & rars-1(gc47) & gc47;gcSi2 & gc47;gcls3 & gc47;gcSi4 \\
\hline Pumping (pumps/min) & $24 \mathrm{~h}$ & $163 \pm 40(50.5)$ & $159 \pm 54(50.5)$ & $18 \pm 44(54.5)$ & $14 \pm 26(30.3)$ \\
\hline Unc (\%) & $72 \mathrm{~h}$ & $8 \pm 10(397.7)$ & $7 \pm 9(355.7)$ & $40 \pm 11(423.7)^{c}$ & $29 \pm 6(246.4)^{c}$ \\
\hline Velocity $(\mathrm{mm} / \mathrm{s})$ & $72 \mathrm{~h}$ & $0.16 \pm 0.050(30.3)$ & $0.15 \pm 0.046(30.3)$ & $0.01 \pm 0.015(30.3)^{c}$ & $0.01 \pm 0.012(30.3)^{c}$ \\
\hline Body bend $/ \mathrm{min}$ & $48 \mathrm{~h}$ & $18.1 \pm 2.43(10.1)$ & $15.4 \pm 3.30(20.2)$ & $0.4 \pm 1.32(40.4)^{\mathrm{c}}$ & $0.7 \pm 1.59(10.1)^{c}$ \\
\hline Death $(\%)$ & $96 \mathrm{~h}$ & $2.8 \pm 3.58(397.7)$ & $2.4 \pm 3.79(355.7)$ & $57.3 \pm 23.68(423.7)$ & $39.0 \pm 18.85(246.4)$ \\
\hline PID (\%) & $96 \mathrm{~h}$ & $0(508.8)$ & $0(449.8)$ & $26.9 \pm 13.74(545.8)$ & $27.3 \pm 14.41(259.4)$ \\
\hline Pharyngeal cell swelling (\%) & $72 \mathrm{~h}$ & $6.0 \pm 8.94(100.5)$ & $10.0 \pm 13.22(60.3)$ & $48.3 \pm 14.43(60.3)$ & $51.7 \pm 15.28(60.3)$ \\
\hline Tail cell swelling (\%) & $72 \mathrm{~h}$ & $6.0 \pm 6.52(100.5)$ & $3.3 \pm 5.77(60.3)$ & $35.0 \pm 5.00(60.3)$ & $43.3 \pm 14.33(60.3)$ \\
\hline GABA neuropathology $(\%)^{\mathbf{b}}$ & $48 \mathrm{~h}$ & $11.7 \pm 5.77(60.3)$ & $0(60.3)$ & $60.0 \pm 15.00(60.3)$ & $70.0 \pm 13.23(60.3)$ \\
\hline
\end{tabular}

Abbreviations: GABA, gamma-aminobutyric acid; Unc, uncoordinated; PID, pharyngeal intestinal detachment

${ }^{a}$ Recovery from a $21 \mathrm{~h}$ hypoxic insult

${ }^{b}$ GABA neuron visualized by a transgene oxls12 [P unc-47::GFP]

${ }^{C}$ Severe Unc (uncoordinated) animals scored. Data are mean \pm S.D. (no. of animals, no. of trials) 
a

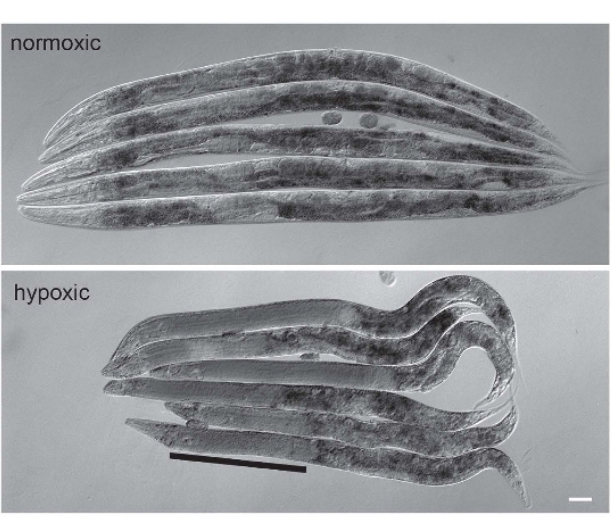

C

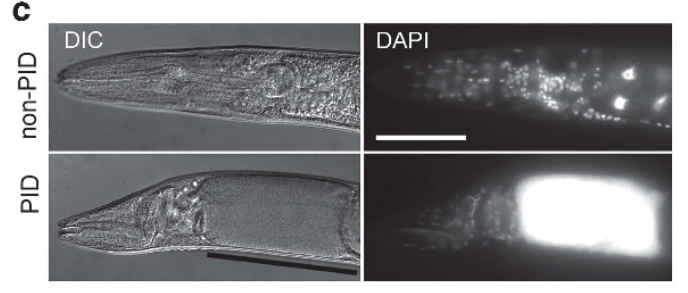

d

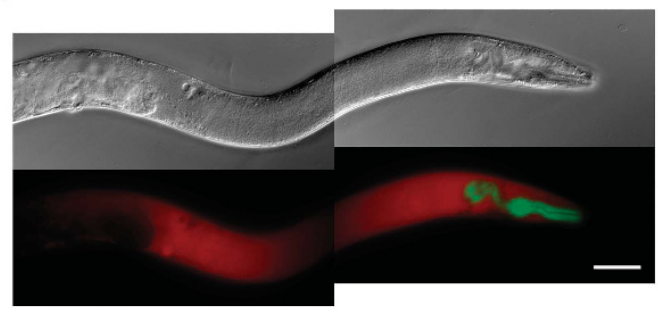

f

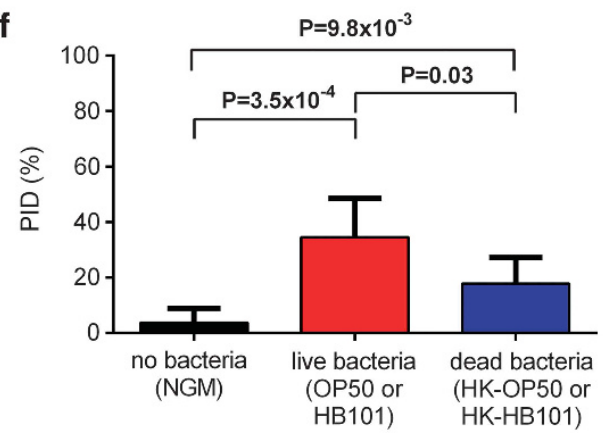

b

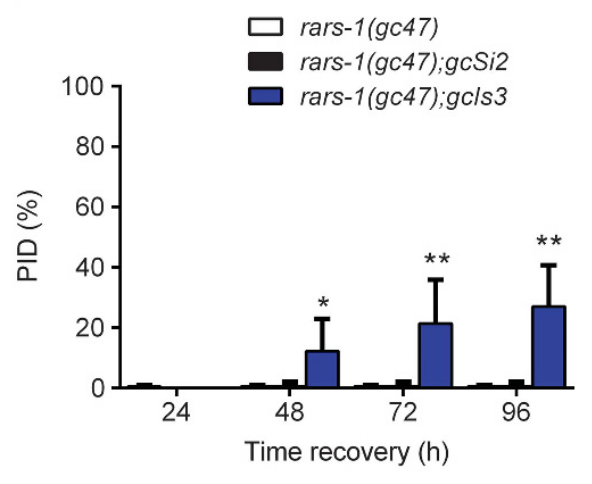

e
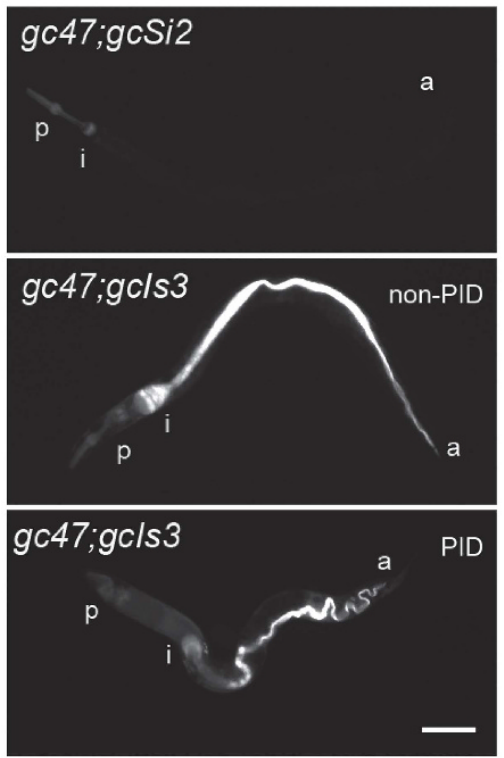

$\square$ Unc $\square$ dead

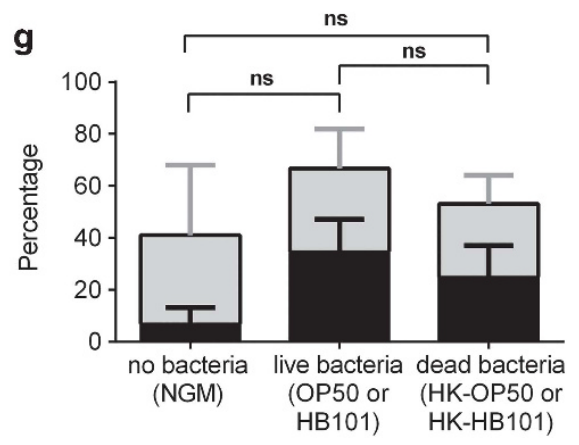

Figure 2 Hypoxic PID phenotype. (a) Examples of PID (black bar) in gc47;gcls3 animals after $48 \mathrm{~h}$ recovery from normoxic or hypoxic incubations (scale bar $=50 \mu \mathrm{m}$ ). (b) Quantification of PID phenotype. The fraction of worms of indicated genotypes bearing PID is plotted. Bars represent mean \pm S.D. of eight independent experiments ( $n \geqq 449$ animals). $P$-values compared with $24 \mathrm{~h} ;{ }^{*} P<0.05 ;{ }^{* *} P<0.01$, two-tailed $t$-test $\left(48 \mathrm{~h}-P=0.015,72 \mathrm{~h}-P=0.004\right.$ and $\left.96 \mathrm{~h}-P=8.6 \times 10^{-4}\right)$. (c) $\mathrm{PID}$ is filled with DNA. gc47;gcls3 without or with PID (black bar) were stained with DAPI and imaged. (white scale bar $=100 \mu \mathrm{m}$ ). (d) Bacteria-filling PID. Hypoxic gc47;gcls3 bearing PID after a $48 \mathrm{~h}$ recovery on HB101-mCherry bacterial food was imaged by DIC (upper panel) and by epifluorescence. (Scale bar $=100 \mu \mathrm{m}$ ). (e) Visualization of PID. gc47;gcSi2 or gc47;gcls3 pre-fed with HB101-mCherry before hypoxic incubation then imaged after a 72 recovery from hypoxia on unlabeled OP50 bacteria. gc47;gcSi2 animals have cleared HB101-mCherry, but gc47;gcls3 have not. Non-PID animal has intact intestine. (scale bar $=100 \mu \mathrm{m}$ ). p, pharynx; I, intestine; a, anus. (f) Effect of bacteria on PID. The fraction of rars-1 (gc47);gcls3 bearing PID after a $72 \mathrm{~h}$ recovery from hypoxia. Bars represent mean \pm S.D. of five independent experiments ( $n \geqq 193$ animals). $P$-values by two-tailed $t$-test. (g) Effect of bacteria on Unc and organismal death. The fraction of Unc and organismal death of rars-1 (gc47); gcls3 after a $72 \mathrm{~h}$ recovery on indicated condition from hypoxia. Bars represent mean \pm S.D. of five independent experiments ( $n \geqq 193$ animals). $P$-values are by two-tailed $t$-test. ns, not significant 
GABA neuronal targeted strain compared with the PM-targeted stain.

Surprisingly, the hypoxic injury phenotypes of GN-targeted rars-1(gc47); gcSi4( $\left.\mathrm{P}_{\text {unc-47::rars-1 }}(+)\right)$ were virtually indistinguishable from those produced by the PM-targeted strain (Table 1, Figure 3). Perhaps most surprisingly, the pumping rate was severely reduced after hypoxia in gc47;gcSi4 to a level similar to that in the $g c 47 ; g c / s 3$ (Table 1). As expected, hypoxia produced axonal morphological defects in gc47;gcSi4 (Figure 3b), but the fraction of hypoxia-treated animals with GABA neuronal pathology was equally high in PM-targeted gc47;gcls3 animals (Figure 3c, Table 1). Similarly, hypoxia produced both delayed Unc, death and PID phenotypes in gc47;gcSi4 at levels similar to gc47;gcls3 (Figures 3d-g, Table 1, Supplementary Videos 1-4).

To attempt to identify primary hypoxic injury in the GNtargeted strain, we scored two phenotypes relatively specific to deficits in $C$. elegans GABAergic transmission. Laser ablation of $C$. elegans $G N$ s or loss-of-function mutations in the unc-25 gene, which encodes the GABA synthetic enzyme glutamic acid decarboxylase, causes an unusual locomotion defect called shrinking where touching the head of the worm causes a brief simultaneous contraction of the muscles cells in all four radial quadrants thereby shortening (shrinking) the worm. ${ }^{23-25}$ We scored shrinking behavior in GN-targeted animals after hypoxia and observed no shrinking in either Unc animals or non-Unc animals (Supplementary Table 1).

The other phenotype present in GABAergic defective animals is defects in defecation, where $>80 \%$ of defecation cycles lack an expulsion step in unc-25 mutant animals compared with $<1 \%$ expulsion defects for wild-type animals (Supplementary Table 2). ${ }^{25}$ After recovery from hypoxia, a substantial fraction of both the PM- and GN-targeted animals had no observable defecation cycles. Defecation cycles themselves are not GN mediated and are indicative of more widespread injury. Of those animals with defecation cycles, we observed significant expulsion defects in the GNtargeted strain (37\% of defecation cycles without an expulsion); however, the PM-targeted strain had no observed expulsion defects. Twenty-five percent of GN-targeted animals had an expulsion defect rate that overlapped with that seen in unc-25(If) animals (range of enteric muscle contraction (EMC)/posterior body contraction $(\mathrm{pBoc})=11-33 \%)$, whereas none of the PM-targeted strains did (Supplementary Table 2). These data demonstrate a more severe expulsion defect in the GN-targeted strain than in the PM-targeted strain consistent with a primary injury to these GABAergic neurons. However, the majority of the animals do have preserved EMCs and therefore preserved GABA neuronal function. Overall, the lack of a hypoxia-induced shrinking phenotype and only a weakly penetrant expulsion phenotype indicate that the GNs are still functional in most animals after recovery from hypoxia. Thus, primary injury to these neurons is relatively minor compared with the secondary injury.

Cell nonautonomous hypoxia-induced necrotic morphology. Necrosis is accompanied by severe cellular swelling and is thought to be characteristic of early primary cell autonomous hypoxic injury. ${ }^{26,27}$ Thus, we hypothesized that necrotic-like cell swelling in the pharynx would be present in the PM-targeted strain and would develop later, if at all, in the surrounding and distant cells. Similarly, we expected that pharyngeal cell swelling would be initially absent in the GN-targeted strain and then appear later, if at all. As expected, significant cell swelling in the pharynx in the PM-targeted strain was observed after hypoxia (Figures $4 a-c$ ). Swelling in cells surrounding the pharynx was also observed initially in the PM-targeted strain (Figure 4a, Supplementary Figure 2). However, we observed no evidence for a propagation of necrotic-like cell injury with an equal level of necrosis in the mid-body adjacent to the pharynx as in the more distal posterior body (Supplementary Figure 2). Surprisingly, pharyngeal cell swelling was also observed immediately after hypoxic incubation in the untargeted and GN-targeted strains (Figure 4b). However, immediately after hypoxia, the fraction of animals with severe (operationally defined as greater than five swollen cells/ pharynx) pharyngeal cell swelling was low in the untargeted strains but virtually $100 \%$ in both the PM- and GN-targeted strains (Figure 4c). After $3 \mathrm{~h}$ of recovery, pharyngeal cell swelling in most untargeted animals had recovered fully, whereas in both the PM-targeted and GN-targeted strains about $90 \%$ of animals retained some swollen pharyngeal cells, although the fraction of these animals with severe pharyngeal swelling had fallen about fourfold (Figures $4 \mathrm{~b}$ and c). Notably, in the wild-type strain N2, $100 \%$ of the animals had immediate severe pharyngeal cell swelling but unlike in the PM- and GM-targeted strains, the cells did not recover after $3 \mathrm{~h}$, indicating that persistence of the pharyngeal necrotic morphology was dependent on the injury of nonpharyngeal cells (Figure 4c).

With $24 \mathrm{~h}$ and longer recovery times, about half of the PMand GN-targeted animals had some pharyngeal swelling. Significant cellular swelling in the tail was similarly prevalent in both the PM- and GN-targeted animals but unlike in the pharynx was delayed until 3 days post hypoxia (Figure 4d). To determine whether the rapid reduction of pharyngeal cell swelling over the first $3 \mathrm{~h}$ was due to recovery or lysis of cells, we longitudinally observed individual pharyngeal cells in PMtargeted animals. During the first $3 \mathrm{~h}$, most swollen pharyngeal cells reduced in size and none were observed to lyse (Figures $4 \mathrm{e}$ and $\mathrm{g}$ ). However, after $48 \mathrm{~h}$ of recovery, the swollen cells remained unchanged in size over a 3-h observation period, suggesting that late swelling is likely a terminal event (Figures $4 f$ and $h$ ). Finally, to determine whether the hypoxia-induced cellular swelling shared mechanistic features with necrosis, we scored the PMtargeted strain in the presence of a loss-of-function mutation of asp-4, which encodes an aspartyl protease required for ion channel-mediated necrosis in C. elegans. ${ }^{28}$ Loss of asp-4 function significantly reduced the fraction of PM-targeted animals with late cell swelling in both the pharynx and the tail (Figure 4i), a result consistent with necrosis as a mechanism for the late cell swelling.

Intestinal and neuronal daf-2 enhances cell nonautonomous hypoxic injuries. The insulin/IGF receptor daf-2 negatively regulates $C$. elegans longevity and hypoxic survival through a mechanism requiring the DAF-16 
a
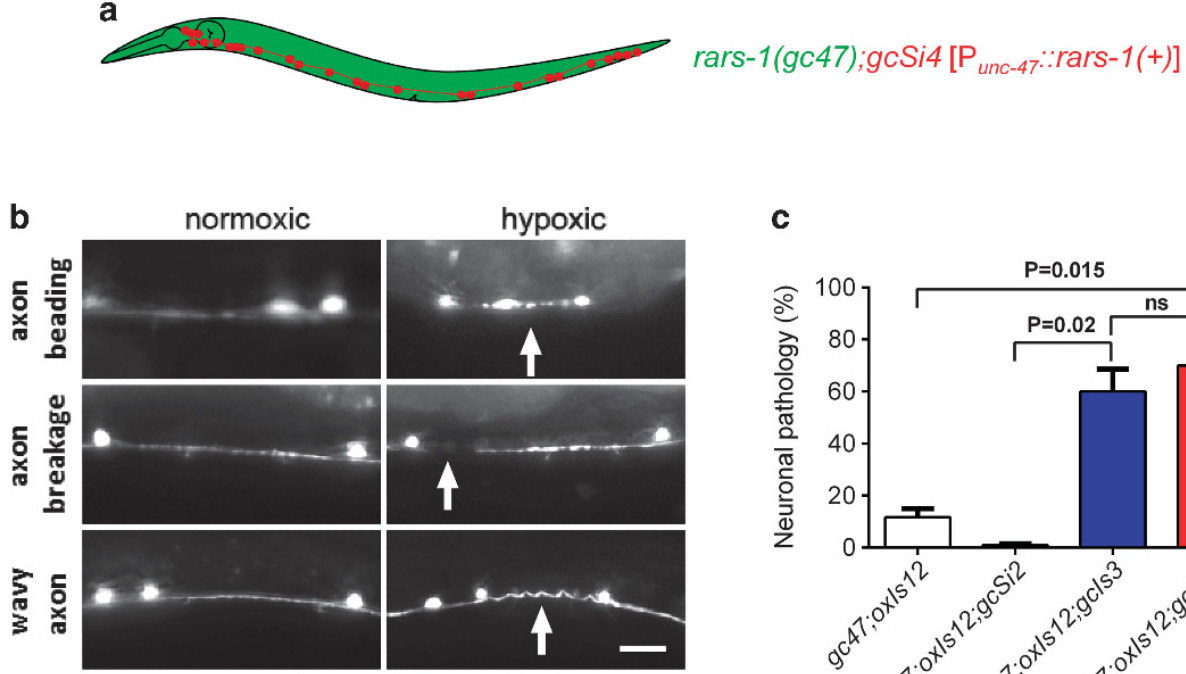

C
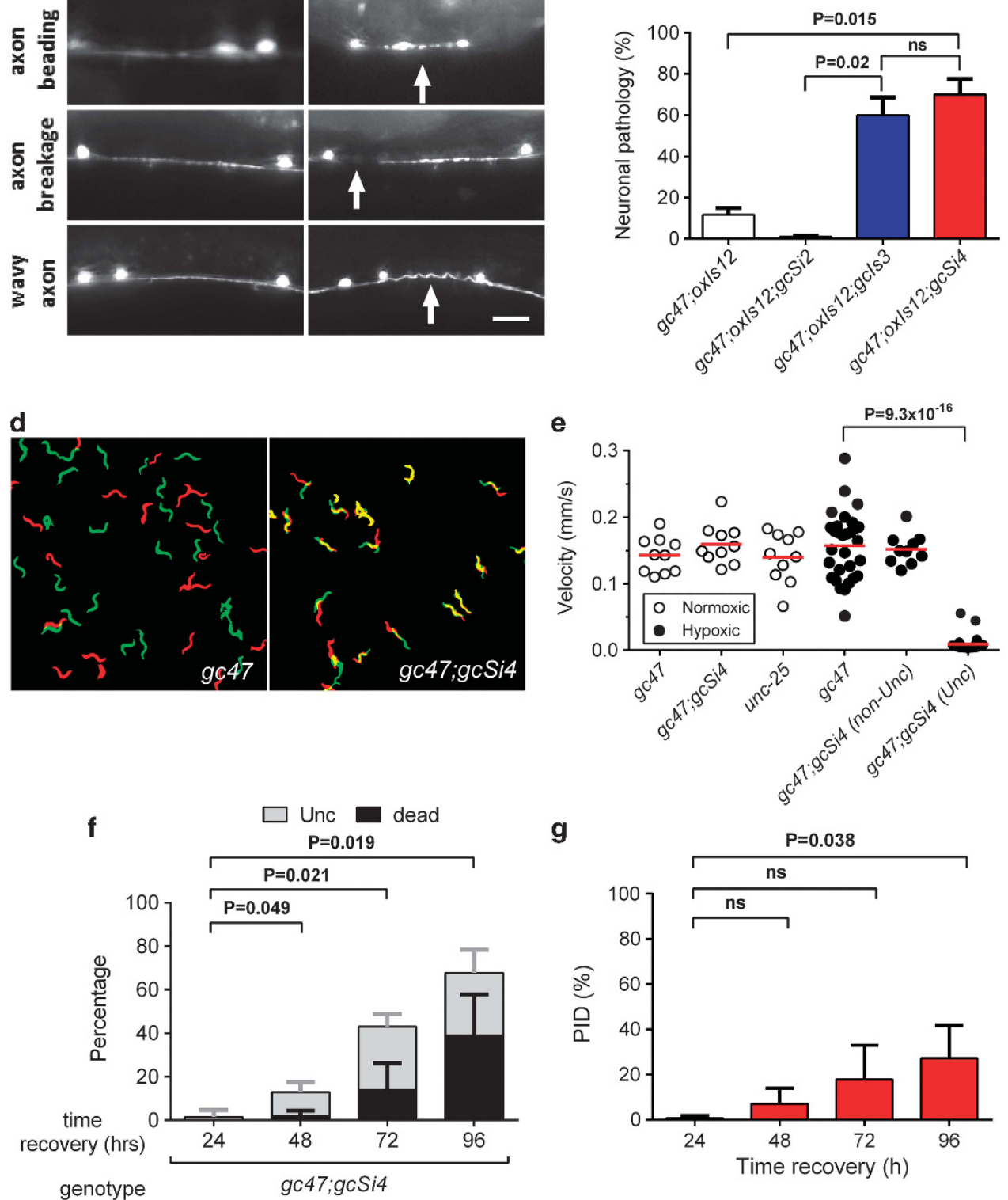

g

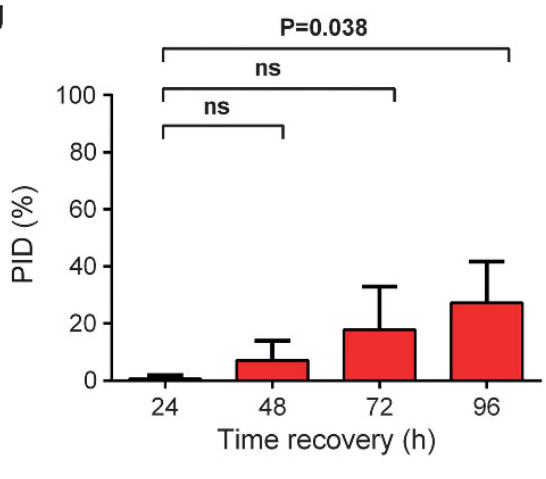

Figure 3 Hypoxic targeting of GABAergic neurons causes cell nonautonomous injuries. (a) Schematic representation of GABAergic neurons (GN)-targeted model. (b) Examples of hypoxic neuronal injuries. Hypoxic axonal injuries of GNs (beading, breakage and waviness of axons, as indicated by arrow) in rars-1(gc47); $g c S i 4$;oxls12 were imaged after a $72 \mathrm{~h}$ recovery from hypoxia. Normoxic control also shown. (Scale bar $=100 \mu \mathrm{m}$ ). (c) Quantification of the neuron pathology (axonal beading, breakage or waviness) after a $72 \mathrm{~h}$ recovery from hypoxia. Bars represent mean \pm S.D. of three independent experiments ( $n=60$ animals). $P$-values by two-tailed $t$-test; $n s$, not significant. (d and e) Hypoxic Unc phenotype. Time lapse images (red @ time 0, green $30 \mathrm{~s}$ later) were taken after a $72 \mathrm{~h}$ recovery from hypoxia and overlaid. Velocity assay quantifying Unc phenotype of animals with indicated genotypes after a $72 \mathrm{~h}$ recovery from normoxic or hypoxic incubation. Normoxic unc-25(e156) locomotion was scored to show the minimal effect of GABAergic defective transmission on locomotion velocity. All hypoxic gc47;gcSi4 animals were categorized as either non-Unc or Unc and assayed separately. $P$-values are by two-tailed $t$-test. Red line indicates mean of $n=10$ and 30 animals for normoxic (one trial) and hypoxic condition (three trials, $n=10$ per trial for each strain tested), respectively. $n=10$ (one trial) for hypoxic non-Unc gc47;gcSi4 animals. $P$-values by two-tailed $t$-test. (f) Hypoxic Unc and delayed organismal death. Bars represent mean \pm S.D. of four independent experiments $(n=246$ animals). $P$-values are by two-tailed $t$-test for the sum of the $\%$ Unc and dead. Corresponding $P$-values for \% dead are: $48 \mathrm{~h}-P=0.22,72 \mathrm{~h}-P=0.11$ and $96 \mathrm{~h}-P=0.025$. For $\%$ Unc are: $48 \mathrm{~h}-P=0.068,72 \mathrm{~h}-P=0.0038$ and $96 \mathrm{~h}-P=0.016$. (g) Quantification of PID phenotype. The fraction of hypoxic gc47;gcSi4-bearing PID is plotted. Bars represent mean \pm S.D. of four independent experiments $(n=259$ animals). $P$-values are by two-tailed $t$-test; ns, not significant 

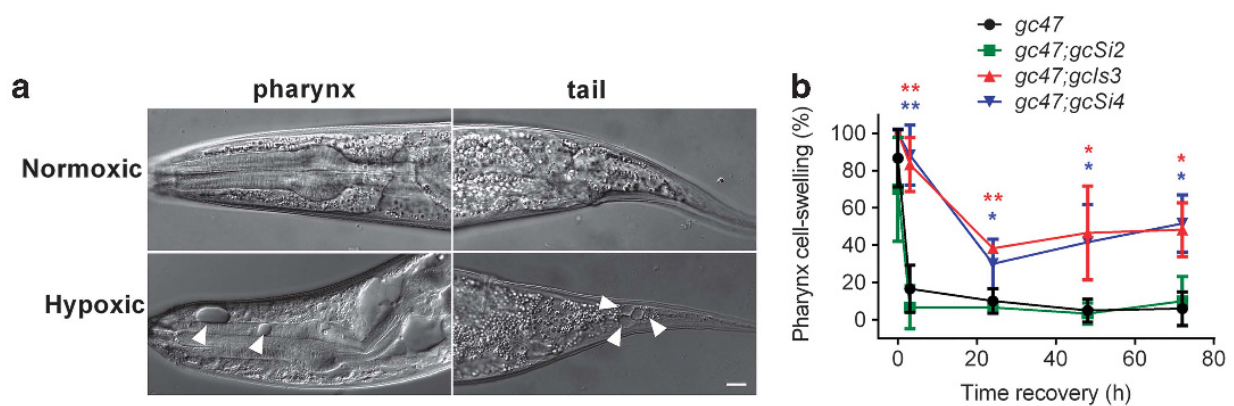

c

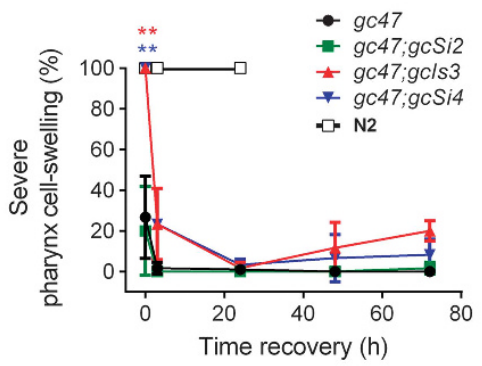

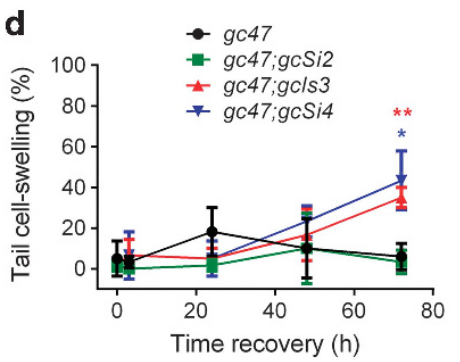

e
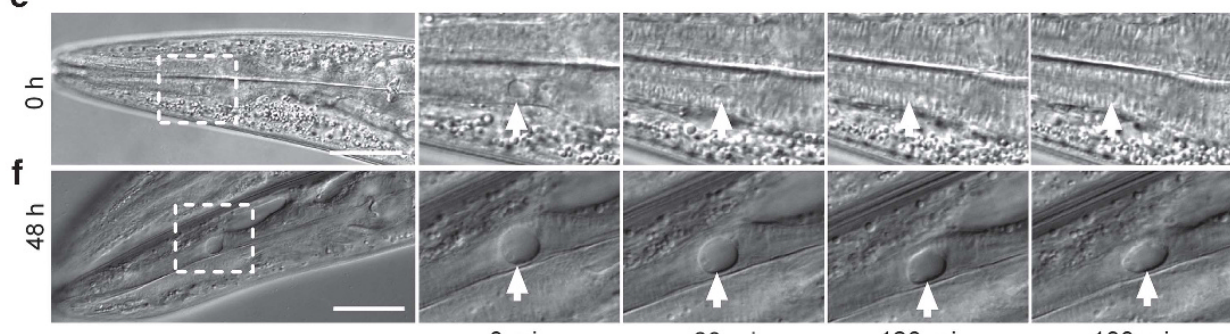

0 min

$60 \mathrm{~min}$

120 min

$180 \mathrm{~min}$

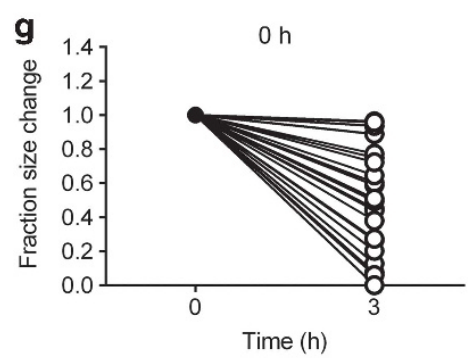

h

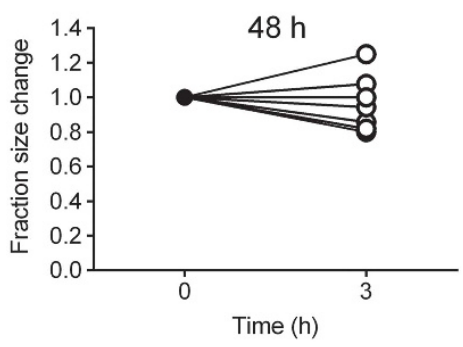

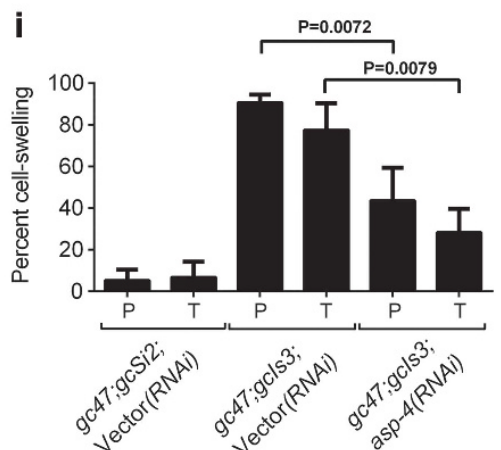

Figure 4 Hypoxic cell swelling in the PM-targeted and GN-targeted animals. (a) Hypoxic cell swelling observed in the pharynx and tail of gc47;gcls3. Arrowheads indicate swollen cells. (Scale bar $=20 \mu \mathrm{m}$ ). (b-d) Pharyngeal and tail cell swelling. Percentage of worms with any (b) or severe ( $>5$ cells) (c) pharyngeal cell swelling or (d) any tail cell swelling at different recovery times post hypoxia. Data represent mean \pm S.D. of three independent experiments ( $n=60$ animals). $P$-values versus gc47;gcSi2: ${ }^{\star} P<0.05 ;{ }^{\star *} P<0.01$, two-tailed $t$-test. (b) gc47;gcls3-red, $3 \mathrm{~h}-P=0.0019 ; 24 \mathrm{~h}-P=1.8 \times 10^{-4} ; 48 \mathrm{~h}-P=0.044,72 \mathrm{~h}-P=0.028 ;$ gc47;gcSi4-blue, $3 \mathrm{~h}-P=0.002 ; 24 \mathrm{~h}-P=0.041 ; 48 \mathrm{~h}-P=0.034,72 \mathrm{~h}-P=0.023)$. (c) - gc47;gcls3-0 h $-P=0.003 ; g c 47 ; g c S i 4-0 \mathrm{~h}-P=0.003$. (d) gc47;gcls3-72 $\mathrm{h}-P=0.0019$; gc47;gcSi4 - 72 $\mathrm{h}-P=0.011$. (e-h) Longitudinal imaging of pharyngeal cell swelling over a 3-h period from 0 to $3 \mathrm{~h}$ recovery or $48-51 \mathrm{~h}$ recovery in the $\mathrm{PM}$-targeted strain. White arrows indicate the location of the swollen cells. Quantitative analysis of the change over $3 \mathrm{~h}$ in the area of each swollen cell after a $0 \mathrm{~h}(\mathrm{~g}, n=27)$ and after a 48 recovery (h, $n=10)$. (i) Effect of asp-4(RNAi) on late hypoxic cell swelling 72 post hypoxia. Worms fed from egg to adult with vector (L4440) or asp-4(RNAi). Bars represent mean \pm S.D. of five independent experiments $(n=100$ animals). $P$-values are by two-tailed $t$-test

FOXO transcription factor. $9,29,30$ However, when daf-2 functions relative to the hypoxic injury to regulate hypoxic survival and whether this function is cell autonomous or not is unknown. We used the PM-targeted strain to answer these questions. First, we asked when daf-2 controls hypoxic survival by RNAi treatment at various times relative to the hypoxic incubation. In wild-type animals, daf-2(RNAi) only before hypoxia (D2 $>$ V) or before and after (D2 $>$ D2), but not after-only $(\mathrm{V}>\mathrm{D} 2)$ reduced hypoxia-induced animal death (Figure 5a). In PM-targeted animals, daf-2(RNAi) either before-only $(\mathrm{D} 2>\mathrm{V})$ or before and after (D2 $>\mathrm{D} 2)$ robustly protected from hypoxic death. daf-2(RNAi) only after hypoxia (V>D2) had a weaker but still significant hypoxia protective effect (Figure 5b). In addition, daf-2(RNAi) only after hypoxia 


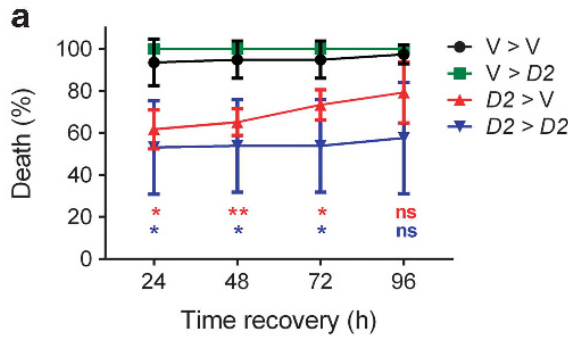

c

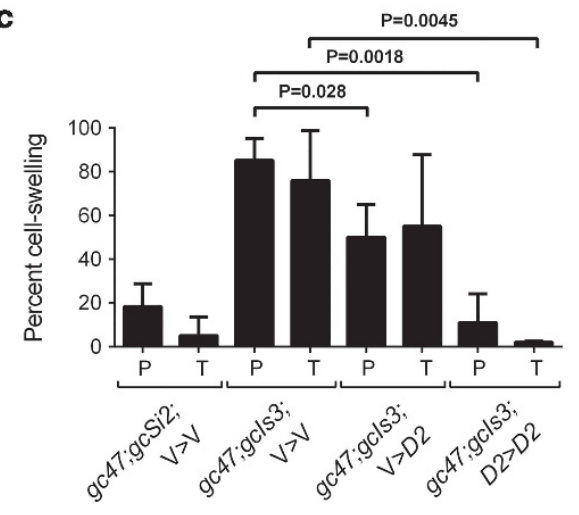

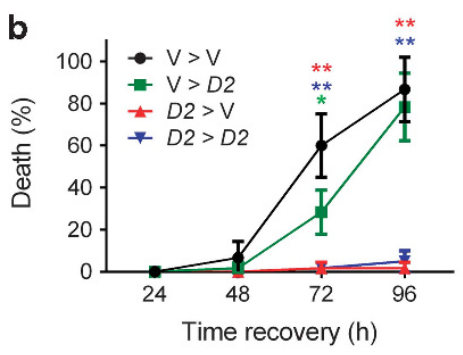

d

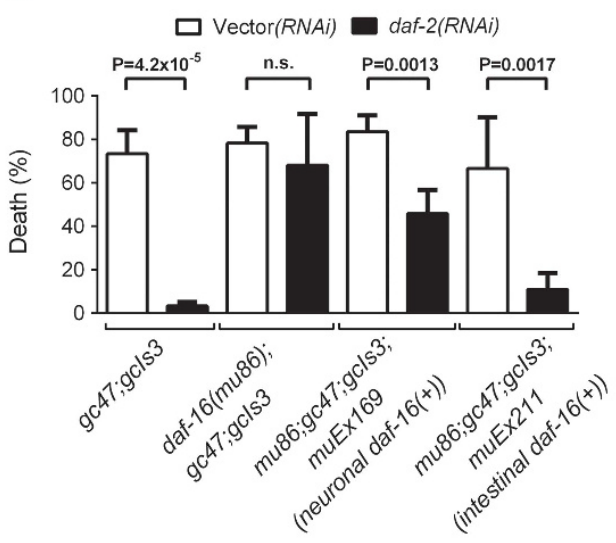

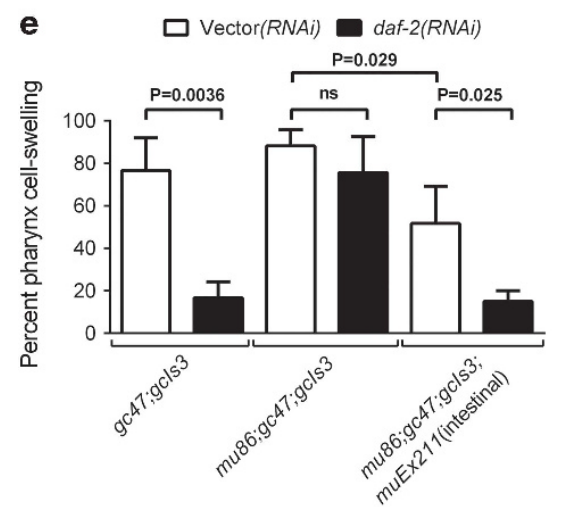
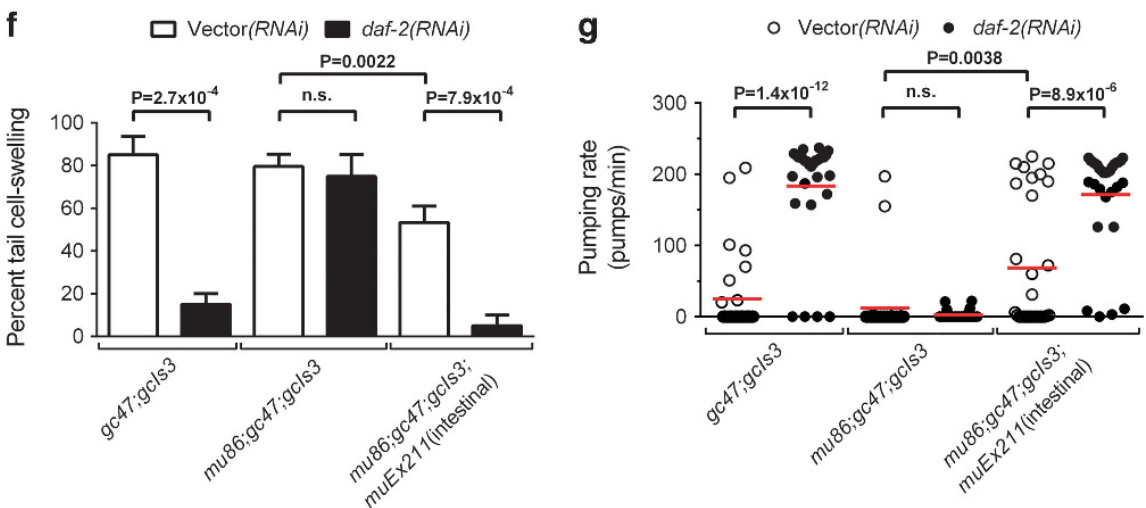

Figure 5 The effect of the daf-2 signaling pathway on delayed hypoxic injury. (a and $\mathbf{b})$ daf-2(RNAi) is sufficient to attenuate the delayed death. N2 (a) and gc47; $g c / s 3$ (b) were fed with daf-2(RNAi) (D2) after hypoxia (V>D2), before (D2 $>$ V) or before and after (D2 $>$ D2) or with vector (V) before and after (V>V). Organismal death scored at indicated recovery times. Data represent mean \pm S.D. of three independent experiments ( $n \geqq 80$ animals for $\mathrm{N} 2$ and $n=60$ for gc47;gcls3). $P$-values are by two-tailed $t$-test. ns, not significant. $P$-value versus V $>V$. ${ }^{*} P<0.05 ;{ }^{*} P<0.01 ;(a)-D 2>V$, red, $24 \mathrm{~h}-P=0.018,48 \mathrm{~h}-P=0.009,72 \mathrm{~h}-P=0.031 ; \mathrm{D} 2>\mathrm{D} 2$, blue, $24 \mathrm{~h}-P=0.047,48 \mathrm{~h}$ $-P=0.04,72 \mathrm{~h}-P=0.04$. ns, not significant. (b) $-\mathrm{V}>\mathrm{D} 2$, green, $72 \mathrm{~h}-P=0.04 ; \mathrm{D} 2>\mathrm{V}$, red, $72 \mathrm{~h}-P=0.003,96 \mathrm{~h}-P=0.0007 ; \mathrm{D} 2>\mathrm{D} 2$, blue, $72 \mathrm{~h}-P=0.003$, $96 \mathrm{~h}-P=0.0009$. (c) Effect of timing of daf-2(RNAi) on hypoxic cell swelling of gc47;gcls3. Percentage of pharyngeal $(\mathrm{P})$ or tail $(\mathrm{T})$ cell swelling $72 \mathrm{~h}$ post hypoxia in gc47;gcls3 worms fed with indicated RNAi. Bars represent mean \pm S.D. of three independent experiments ( $n \geqq 54$ animals). P-values are by two-tailed $t$-test. (d) Knockdown of daf-2 specifically in neurons or intestine is sufficient to reduce the delayed $(96 \mathrm{~h})$ organismal death. daf-2 RNAi before and after hypoxia. Bars represent mean \pm S.D. of three to four independent experiments ( $n \geqq 93$ animals). $P$-values are by two-tailed $t$-test. ns, not significant. (e and $\mathbf{f}$ ) Specific knockdown of daf-2 signaling in the intestine is sufficient to block pharyngeal and tail injury. Percentage of pharyngeal (e) and tail cell swelling (f) $72 \mathrm{~h}$ after hypoxia in worms fed with RNAi before and after hypoxia. Bars represent mean \pm S.D. of three independent experiments ( $n \geqq 54$ animals). $P$-values are by two-tailed $t$-test. $n s$, not significant. (g) Pharyngeal pumping rate of animals with indicated genotypes and RNAis $24 \mathrm{~h}$ post hypoxia. Red line indicates mean of $n=30$ animals (three trials, $n=10$ per trial for each strain tested). $P$-values are by two-tailed $t$-test. ns, not significant

(V>D2) significantly reduced pharyngeal cell swelling (Figure 5c). Thus, daf-2 can function after the hypoxic injury to improve animal recovery as opposed to simply preventing hypoxic injury.

We next asked whether daf-2 can act cell nonautonomously to control hypoxic sensitivity by combining the PM-targeted strain with cell-specific expression of the daf- 16 gene ${ }^{30}$ which is required for the hypoxia protective phenotype of daf-2 reduction-of-function. ${ }^{9}$ In a daf-16(mu86 null) background, selective expression of wild-type DAF-16 in either neurons or intestinal cells significantly restored daf-2(RNAi) protection against hypoxic animal death in the PM-targeted strain (Figure 5d). Intestinal-specific expression of wild-type daf-16 also restored the protective effect of daf-2(RNAi) against 
pharyngeal and tail cell swelling and pharyngeal pumping defects (Figures $5 \mathrm{e}$ and $\mathrm{g}$ ). These results indicate that daf-2 functions by a cell nonautonomous mechanism to block innocent bystander cell death.

\section{Discussion}

We have developed strains and methods that provide the first genetically tractable approach to study hypoxic injury where delayed secondary cell injury can be definitively observed and manipulated. Using these methods, we were surprised to find that widespread necrotic-like cell injury, severe behavioral deficits and organismal death can be produced by targeting less than three percent of somatic cells, none of which are normally required for organismal viability. Our results suggest that a potent and/or amplifying cell nonautonomous mechanism is responsible for the secondary cell injury. We will focus this discussion on what might be the nature of this cell nonautonomous mechanism and how our model could serve to define the mechanism and discover inhibitors.

Three distinct types of factors might mediate the secondary cell nonautonomous hypoxic death observed in our new model. First, injury promoting factors might be transferred via cell-cell contact, such as gap junctions or membranemembrane interactions. This sort of mechanism has been proposed for both neuronal and myocardial injury during ischemia. ${ }^{31-33}$ In such a mechanism, one would observe a wave of injury emanating from the primarily injured cells spreading to contiguous cells. Clearly, this is not the mechanism of secondary injury in our model. GNs do not contact or synapse onto PMs or indeed any cell in the pharynx nor vice versa. ${ }^{11,12,23,24}$ Yet, GN-targeted animals have a necrotic-like morphology in the pharynx that occurs with the same time course after hypoxia as in the PM-targeted strain. Further, in the PM-targeted animals, although cells surrounding the PMs do have a higher prevalence of necrotic morphology in the first $24 \mathrm{~h}$ of recovery from hypoxia, there is no apparent propagation of necrosis toward the tail of the animal.

Another potential mechanism of cell nonautonomous injury is the release of intracellular toxic molecules upon necrotic lysis of cells. Some of the PMs do appear to undergo necrosis and could, in principle, leak a sufficient amount of toxins to cause secondary injury. However, we did not observe necrotic morphology in the GNs in the GN-targeted animals. Moreover, the lack of a shrinking or highly penetrant defecation defect in the GN-targeted animals following hypoxia indicates that many of the GNs are still functional. Thus, although we cannot rule out cell lysis and release of toxic cellular contents as a mediator of secondary death, at least for the GNs, this explanation seems unlikely.

A third potential mechanism is that a specific signal (we will call this type of signaling molecule a hypoxiakine) from hypoxically injured but not dead cells promotes secondary cell death. The important distinction between a hypoxiakine mechanism and the necrotic toxin mechanism is that hypoxiakine release and secondary cellular response could be regulated as opposed to simply leaking out of a dead necrotic cell. Glutamate-mediated excitoxicity falls into this category. ${ }^{3,34-36}$ In $C$. elegans, the nature of the putative hypoxiakine is unclear but is certainly not vesicular glutamate, as none of the GNs are known to package glutamate into vesicles (http://www.wormatlas.org/neurotransmitterstable. htm), neither, of course, do PMs.

Our results with cell type-specific rescue of daf-16 function show that daf-16 activity in either the intestine or the nervous system can protect distinct cell types. Thus, in the broad sense, we have shown that the daf-2/daf-16 pathway acts cell nonautonomously to control hypoxic cell death as has been previously demonstrated for lifespan extension. ${ }^{30,37-38}$ The cell nonautonomous activity of the daf-2/daf-16 pathway for lifespan can be accounted for by the transcriptional regulatory activity of the DAF-16 FOXO transcription factor. DAF-16 regulates genes that encode proteins that act cell nonautonomously either to activate DAF-16 in other cells or to function independently in other cells to control organismal lifespan and cell degeneration. ${ }^{30,39,40}$ In our experiments where PMs are targeted for primary injury, we find that both targeted (pharyngeal cells) and untargeted (tail cells) cellular swellings are reduced by intestinal DAF-16 activity. This nominally nonautonomous activity of DAF-16 could be the result of the DAF-16-dependent synthesis and release of a hypoxia protective molecule emanating from the intestine to protect other cell types, as proposed for lifespan extension. Alternatively, DAF-16 could be functioning autonomously to protect intestinal cells from secondary injury and appear to act nonautonomously because of reduced release of an intestinal toxin or hypoxiakine that promotes injury of the pharynx and tail. The one type of mechanism that is clearly not operant is nonautonomous activation of DAF-16 in pharyngeal and tail cells, as besides the intestine all other cells lack DAF-16. Future studies will categorize other Hyp genes and small molecules with regards to when they act relative to hypoxia to control cell injury and whether they can protect from innocent bystander death.

\section{Materials and Methods}

Expression constructs. The rars- 1 cDNA was amplified by PCR (primers see Supplementary Table 3) from clones yk1569a07 and yk1124h08 (a gift from Y Kohara, National Institute of Genetics, Mishima, Japan), sequenced and cloned into pPD95.77 (contains unc-54 3'-UTR, Addgene, Cambridge, MA, USA) with $\mathrm{Kpnl}$ and blunt Ecol sites to generate plasmid pMC1001. The rars-1 CDNA together with unc-54 3'-UTR was fused with the myo-2 promoter in pPD132.102 (Addgene) to yield pMC1002, in which the YFP and unc-54 3' -UTR were removed with Kpnl and Apal sites. The unc-47 promoter (1587 bp upstream of the start codon) ${ }^{22}$ was amplified from genomic DNA of N2 by PCR and fused with YFP in pPD132.102 (Addgene), in which the myo-2 promoter was removed by $X$ bal and $K p n l$ to yield pMC1003. In pilot experiments, tissue-specific expression pattern of YFP driven by the cloned unc-47 promoter in GABAergic neurons was confirmed in pilot experiments with a transgenic strain carrying an extrachromosomal array (MC390-ttTi5605; unc-119(ed3);gcEx149[P unc-47::YFP, unc-119(+)). The unc-47 promoter of pMC1003 was then subcloned by Xbal/Kpnl digest into pMC1002 to replace the myo-2 promoter to yield pMC1004 ( $\mathrm{P}_{\text {unc-47 }}:$ rars

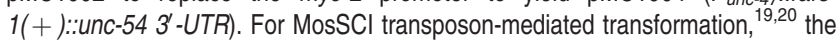

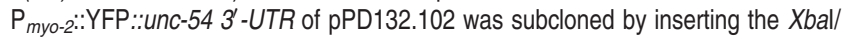
Spel fragment into the Spel site of pCFJ151(II) to yield pMC1005 (pCFJ151-P ::yfp::unc-54 $\left.3^{\prime}-U T R\right)$. pMC1002, which contains $\mathrm{P}_{\text {myo-2::rars-1(+)::unc-54 }}$ $3^{\prime}-$ UTR was subcloned by Xbal and Apal into Spel/BsWI cut pMC1005 to yield

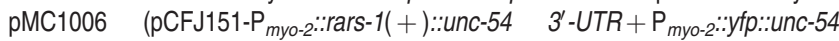
$3^{\prime}$-UTR). $P_{\text {unc-47:: rars-1 }}(+)::$ unc-54 3'-UTR of pMC1004 was subcloned by cutting with $X$ bal/BsilM and inserting into Spel/BsiWI cut pCFJ178(IV) to yield pMC1007. Note that pMC1007 does not have the tandem YFP expression cassette. All constructs were confirmed by restriction digests. Details about primer sequences are available in (Supplementary Table 3). 
Strains and transformation. C. elegans strains were cultured and maintained at $20^{\circ} \mathrm{C}$ on nutrient growth media (NGM) agar with OP50 Escherichia coli food unless otherwise noted. ${ }^{41}$ The N2 (Bristol) strain was the standard wild-type strain. ${ }^{42}$ The alleles that were used in this study are LGI: daf-16(mu86);

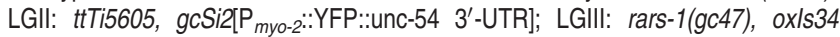

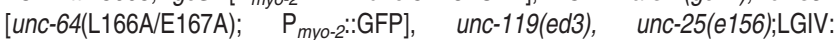
cxTi10882, gcSi4[P $\mathrm{P}_{\text {unc-47::.rars-1 }}+$ )::unc-54 3'-UTR]; LGX: oxls12[P unc-47:.GFP, lin-15(+)]; muEx169 [P unc-119::GFP::daf-16 cDNA, pRF4 rol-6(su1006gf)],

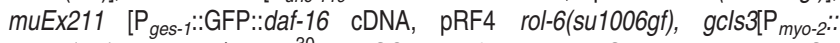
rars- $1(+)::$ unc-54 $\left.3^{\prime}-U T R\right] .^{30}$ MosSCl transformants gcSi2, gcls3 and gcSi4 were generated based on published protocols. ${ }^{19}$ The MosSCl insertion strains EG4322 (ttTi5605;unc-119(ed3) II)or EG5003 (unc-119(ed3);cxTi10882 IV) were used for injection. Single-copy insertions in gcSi2 and gcSi4) were verified by longfragment PCR as described by M. Nonet (http://thalamus.wustl.edu/nonetlab/ ResourcesF/PCR\%20of\%20MosSCI\%20transgenes.pdf). gcls3, derived from the MosSCl protocol, did not integrate at the intended locus on chromosome II; the precise integration site of gcls3 has not been determined. daf-16(mu86); rars-1(gc47);gcls3;muEx169 was constructed by crossing $g c 47 /+; g c l s 3 /+$ males with daf-16(mu86); $m u$ Ex169 and picking YFP expressing rollers, confirming the presence of gc47 and mu86 by PCR, then homozygosing all chromosomal loci. daf-16(mu86);rars-1(gc47);gcls3;muEx211 was made similarly. Genotypes were confirmed by sequencing and PCR.

RNAi experiments. From the Ahringer $C$. elegans RNAi library (MRC Gene service, Geneservice Ltd, Cambridge, UK), ${ }^{43}$ bacterial clones containing RNAi plasmids were cultured and induced with $0.1 \% \beta$-lactose in S-Basal $100 \mathrm{mg} / \mathrm{ml}$ ampicillin for $24 \mathrm{~h}$ at $23^{\circ} \mathrm{C} .{ }^{7}$ Worms were synchronized on RNAi plates for 3.5 days (N2) or 5 days (animals in a rars-1(gc47) background) until reaching adulthood; worms not reaching adulthood were excluded.

Hypoxic incubations. Worms were subjected to hypoxia as described previously except that hypoxic incubation temperature was $26.5^{\circ} \mathrm{C} .{ }^{9}$ Briefly, each plate of worms was washed into one $1.5 \mathrm{ml}$ tube with $1 \mathrm{ml}$ of M9 buffer $(22 \mathrm{mM}$ $\mathrm{KH}_{2} \mathrm{PO}_{4}, 22 \mathrm{mM} \mathrm{Na}_{2} \mathrm{HPO}_{4}, 85 \mathrm{mM} \mathrm{NaCl}, 1 \mathrm{mM} \mathrm{MgSO}_{4}$ ). Worms were allowed to settle by gravity, and $900 \mu \mathrm{l}$ of $\mathrm{M} 9$ was removed. The tubes were then placed in the anaerobic chamber (Forma Scientific, Thermo Fisher Scientific Inc., Waltham, MA, USA) at $26.5^{\circ} \mathrm{C}$ for $21 \mathrm{~h}$ unless otherwise indicated. Oxygen tension was always $\leq 0.3 \%$. Following the hypoxic insult unless otherwise noted, worms were placed on NGM plates spotted with OP50 bacteria using glass Pasteur pipettes and recovered at $20^{\circ} \mathrm{C}$ for the indicated time. Normoxic incubations were otherwise identical except when performed in a $26.5^{\circ} \mathrm{C}$ in a room air incubator.

\section{Hypoxic injury phenotyping}

Pharyngeal pumping rates: Pumping was counted over a 1-min interval. ${ }^{44}$ Ten worms per condition and time point were scored.

Locomotion: Animals with no significant spontaneous movement but with movement in response to touch with a platinum wire were scored as Unc. The speed of locomotion was measured as described ${ }^{45}$ by transferring 10 randomly chosen worms for each condition to an agar plate without bacteria. After a 5-min quiescent period, $30 \mathrm{~s}$ digitized movies (1 frame/s) were taken of each animal's unstimulated movement, and the distance traveled each second was measured and averaged over the 30 frames to obtain a mean speed for each animal by using ImageJ (NIH; http://rsbweb.nih.gov/ij/). Body bends of the Unc animals were scored as described previously. ${ }^{46}$

Shrinking: The uncoordinated shrinking phenotype was scored as described previously. ${ }^{25}$ unc-25(e156), a mutant that generates no GABA, was used as a positive control. ${ }^{25}$

GABAergic neuron pathology. GNs were visualized by YFP driven by the unc-47 promoter (ox/s12). Abnormal morphology of GNs after $48 \mathrm{~h}$ recovery from a $21 \mathrm{~h}$ hypoxic incubation was scored, including beading, breakage and waviness of the axon using epifluorescence microscopy.

Organismal death: Animals were scored as dead if pharyngeal pumping, spontaneous and evoked movement (touching with a platinum wire) were not observed.

Pharyngeal intestinal detachment. PID was visualized under the dissecting microscope as a ground glass appearing region spanning from the posterior edge of pharynx to the ruptured intestinal tract. DAPI staining was performed followed by methanol fixation of worms as described by T. Schedl (http://genetics.wustl. edu/tslab/protocols/dissection-staining-in-situ/dapi-staining/). HB101/mCherry bacteria (a gift from Dr. Leon Avery) feeding was performed either pre- or post-hypoxia as described. For bacterial proliferation assays, heat-killed bacteria were obtained by $65^{\circ} \mathrm{C}$ incubation for $1 \mathrm{~h}$; death of bacteria was confirmed by lack of growth on LB-agar.

Pharyngeal and tail cell swelling: Grossly swollen pharyngeal and tail cells (Supplementary Figure 2) were scored with DIC optics at $\times 63$. Only clearly abnormal cells were scored as swollen; mildly distended cells were ignored. Only alive animals were scored with the exception of N2 where at the $24 \mathrm{~h}$ recovery point the animals were dead. Animals with any swollen cells in the particular region were scored as positive; those animals with $>5$ swollen cells were scored as having severe swelling in that region.

Defecation cycle: Animals were scored for defecation on plates with abundant food as previously described ${ }^{44,47}$ except that only the pBoc and expulsion steps of the defecation cycle were scored. Animals were observed for a minimum of $5 \mathrm{~min}$. Cycles with a pBoc without an expulsion step were scored as expulsion defective. If an animal had no pBocs for the entire observation period, it was scored as defecation defective but not expulsion defective and was not included in the calculation of \%EMCs or EMC defective animals.

Statistics. Two-sided unpaired $t$-tests were used for statistical comparisons. Statistics were calculated using GraphPad Prism 6.01 (San Diego, CA, USA) and Excel 2007 (Microsoft, Redmond, WA, USA). Values are expressed as mean \pm S.D. of at least three independent experiments. A $P$-value of $\leq 0.05$ was considered significant.

Acknowledgements. We thank Barbara Scott and Laura Metz for their technical contributions to the work. We also thank Roland Bainton for suggesting the term hypoxiakine. The work was supported by National Institute of Neurological Disorders and Stroke R01 NS045905, by the International Anesthesia Research Society Frontiers in Anesthesia Research Award, and by the Dr. Seymour and Rose T. Brown Professor endowment fund.

\section{Author contributions}

Chun-Ling Sun-generated all transgenic strains and performed all experiments in Figures 1-3 and some portions of all remaining experiments. Euysoo Kim performed the majority of the experiments in Figures 4 and 5. Both Dr. Sun and Kim helped design, troubleshoot and interpret all experiments and wrote substantial portions of the manuscript. C Michael Crowder conceived the overall cell-specific hypoxic targeting strategy, helped design, troubleshoot and interpret all experiments and helped write the manuscript.

1. Lipton P. Ischemic cell death in brain neurons. Physiol Rev 1999; 79: 1431-1568.

2. Broughton BR, Reutens DC, Sobey CG. Apoptotic mechanisms after cerebral ischemia. Stroke 2009; 40: e331-e339.

3. Choi DW, Rothman SM. The role of glutamate neurotoxicity in hypoxic-ischemic neuronal death. Ann Rev Neurosci 1990; 13: 171-182.

4. Lo EH. A new penumbra: transitioning from injury into repair after stroke. Nat Med 2008; 14: $497-500$

5. Miller DL, Roth MBC. Elegans are protected from lethal hypoxia by an embryonic diapause. Curr Biol 2009; 19: 1233-1237.

6. Menuz V, Howell KS, Gentina S, Epstein S, Riezman I, Fornallaz-Mulhauser M et al. Protection of C. elegans from anoxia by HYL-2 ceramide synthase. Science 2009; 324: 381-384.

7. Mabon ME, Mao X, Jiao Y, Scott BA, Crowder CM. Systematic identification of gene activities promoting hypoxic death. Genetics 2009; 181: 483-496.

8. Anderson LL, Mao X, Scott BA, Crowder CM. Survival from hypoxia in C. elegans by inactivation of aminoacyl-tRNA synthetases. Science 2009; 323: 630-633.

9. Scott BA, Avidan MS, Crowder CM. Regulation of hypoxic death in C. elegans by the insulin/IGF receptor homolog DAF-2. Science 2002; 296: 2388-2391.

10. Wojtovich AP, DiStefano P, Sherman T, Brookes PS, Nehrke K. Mitochondrial ATP-sensitive potassium channel activity and hypoxic preconditioning are independent of an inwardly rectifying potassium channel subunit in Caenorhabditis elegans. FEBS Lett 2012; 586: 428-434.

11. Avery L, You YJ. C. elegans feeding. WormBook 2012; 1-23; doi:10.1895/wormbook.1.150.1.

12. Albertson DG, Thomson JN. The pharynx of Caenorhabditis elegans. Philos Trans $R$ Soc Lond B Biol Sci 1976; 275: 299-325.

13. Avery L, Horvitz HR. A cell that dies during wild-type C. elegans development can function as a neuron in a ced-3 mutant. Cell 1987; 51: 1071-1078. 
14. Avery L, Horvitz HR. Pharyngeal pumping continues after laser killing of the pharyngeal nervous system of $C$. elegans. Neuron 1989; 3: 473-485.

15. Avery L. Motor neuron M3 controls pharyngeal muscle relaxation timing in Caenorhabditis elegans. J Exp Biol 1993; 175: 283-297.

16. Raizen DM, Avery L. Electrical activity and behavior in the pharynx of Caenorhabditis elegans. Neuron 1994; 12: 483-495.

17. Raizen DM, Lee RY, Avery L. Interacting genes required for pharyngeal excitation by moto neuron MC in Caenorhabditis elegans. Genetics 1995; 141: 1365-1382.

18. Okkema PG, Harrison SW, Plunger V, Aryana A, Fire A. Sequence requirements fo myosin gene expression and regulation in Caenorhabditis elegans. Genetics 1993; 135 : 385-404.

19. Frokjaer-Jensen C, Davis MW, Ailion M, Jorgensen EM. Improved Mos1-mediated transgenesis in C. elegans. Nat Meth 2012; 9: 117-118.

20. Frokjaer-Jensen C, Davis MW, Hopkins CE, Newman BJ, Thummel JM, Olesen SP et al. Single-copy insertion of transgenes in Caenorhabditis elegans. Nat Genet 2008; 40 1375-1383

21. Richmond JE, Weimer RM, Jorgensen EM. An open form of syntaxin bypasses the requirement for UNC-13 in vesicle priming. Nature 2001; 412: 338-341.

22. McIntire SL, Reimer RJ, Schuske K, Edwards RH, Jorgensen EM. Identification and characterization of the vesicular GABA transporter. Nature 1997; 389 870-876.

23. McIntire SL, Jorgensen E, Kaplan J, Horvitz HR. The GABAergic nervous system of Caenorhabditis elegans [see comments]. Nature 1993; 364: 337-341.

24. Jorgensen EM. GABA. WormBook 2005; 1-13; doi:10.1895/wormbook.1.14.1.

25. McIntire SL, Jorgensen E, Horvitz HR. Genes required for GABA function in Caenorhabditis elegans [see comments]. Nature 1993; 364: 334-337.

26. Roy M, Sapolsky R. Neuronal apoptosis in acute necrotic insults: why is this subject such a mess? Trends Neurosci 1999; 22: 419-422.

27. Nicotera P, Leist M, Manzo L. Neuronal cell death: a demise with different shapes. Trends Pharmacol Sci 1999; 20: 46-51.

28. Syntichaki P, Xu K, Driscoll M, Tavernarakis N. Specific aspartyl and calpain proteases are required for neurodegeneration in C. elegans. Nature 2002; 419: 939-944.

29. Murphy $\mathrm{CT}$, McCarroll SA, Bargmann $\mathrm{Cl}$, Fraser A, Kamath RS, Ahringer $\mathrm{J}$ et al. Genes that act downstream of DAF-16 to influence the lifespan of Caenorhabditis elegans. Nature 2003; 424: 277-283.

30. Libina N, Berman JR, Kenyon C. Tissue-specific activities of $C$. elegans DAF-16 in the regulation of lifespan. Cell 2003; 115: 489-502.
31. Garcia-Dorado D, Rodriguez-Sinovas A, Ruiz-Meana M. Gap junction-mediated spread of cell injury and death during myocardial ischemia-reperfusion. Cardiovasc Res 2004; 61: 386-401.

32. Talhouk RS, Zeinieh MP, Mikati MA, El-Sabban ME. Gap junctional intercellular communication in hypoxia-ischemia-induced neuronal injury. Prog Neurobiol 2008; 84 $57-76$

33. Belousov AB. Novel model for the mechanisms of glutamate-dependent excitotoxicity: role of neuronal gap junctions. Brain Res 2012; 1487: 123-130.

34. Nishizawa Y. Glutamate release and neuronal damage in ischemia. Life Sci 2001; 69 : 369-381.

35. Sattler R, Tymianski M. Molecular mechanisms of glutamate receptor-mediated excitotoxic neuronal cell death. Mol Neurobiol 2001; 24: 107-129.

36. Arundine M, Tymianski M. Molecular mechanisms of glutamate-dependent neurodegeneration in ischemia and traumatic brain injury. Cell Mol Life Sci 2004; 61: 657-668.

37. Apfeld $\mathrm{J}$, Kenyon $\mathrm{C}$. Cell nonautonomy of $\mathrm{C}$. elegans daf-2 function in the regulation of diapause and life span. Cell 1998; 95: 199-210.

38. Wolkow CA, Kimura KD, Lee MS, Ruvkun G. Regulation of $C$. elegans life-span by insulinlike signaling in the nervous system. Science 2000; 290: 147-150.

39. Zhang P, Judy M, Lee SJ, Kenyon C. Direct and indirect gene regulation by a life-extending FOXO protein in C. elegans: roles for GATA factors and lipid gene regulators. Cell Metab 2013; 17: 85-100.

40. Murphy CT, Lee SJ, Kenyon C. Tissue entrainment by feedback regulation of insulin gene expression in the endoderm of Caenorhabditis elegans. Proc Natl Acad Sci USA 2007; 104: 19046-19050.

41. Stiernagle T. Maintenance of C. elegans. WormBook 2006; 1-11; doi:10.1895/ wormbook.1.101.1.

42. Brenner S. The genetics of Caenorhabditis elegans. Genetics 1974; 77: 71-94.

43. Kamath RS, Fraser AG, Dong Y, Poulin G, Durbin R, Gotta M et al. Systematic functional analysis of the Caenorhabditis elegans genome using RNAi. Nature 2003; 421: 231-237.

44. Crowder CM, Shebester LD, Schedl T. Behavioral effects of volatile anesthetics in Caenorhabditis elegans. Anesthesiology 1996; 85: 901-912.

45. Crowder CM, Westover EJ, Kumar AS, Ostlund Jr RE, Covey DF. Enantiospecificity of cholesterol function in vivo. J Biol Chem 2001; 276: 44369-44372.

46. Metz LB, Dasgupta N, Liu C, Hunt SJ, Crowder CM. An evolutionarily conserved presynaptic protein is required for isoflurane sensitivity in Caenorhabditis elegans. Anesthesiology 2007; 107: 971-982.

47. Thomas JH. Genetic analysis of defecation in Caenorhabditis elegans. Genetics 1990; 124 : 855-872.

Supplementary Information accompanies this paper on Cell Death and Differentiation website (http://www.nature.com/cdd) 